\title{
AUTOMATED RADIOLOGICAL MONITORING AT A RUSSIAN MINISTRY OF DEFENCE NAVAL SITE
}

\author{
P.D. Moskowitz'; J. Pomerville ${ }^{2}$, S. Gavrilov ${ }^{3}$, V.Kisselev ${ }^{3}$, V. Daniylan ${ }^{3}$, A Belikov ${ }^{4}$, A. Egorkin ${ }^{4}$, \\ Y. Sokolovski ${ }^{5}$, M. Endregard ${ }^{6}$, M. Krosshavn ${ }^{7}$, C-V. Sundling ${ }^{7}$ and H. Yokstad ${ }^{7}$ \\ ${ }^{1}$ Brookhaven National Laboratory, Upton, NY \\ ${ }^{2}$ US Department of Defense, Washington, DC \\ ${ }^{3}$ Institute for Nuclear Safety, Moscow, Russia \\ ${ }^{4}$ Russian Navy, Moscow, Russia \\ ${ }^{5}$ ICC Nuklid, Saint Petersburg, Russia \\ ${ }^{6}$ Norwegian Defence Research Establishment, Oslo, Norway \\ ${ }^{7}$ Institute for Energy Technology, Oslo, Norway
}

\begin{abstract}
The Arctic Military Environmental Cooperation (AMEC) Program is a cooperative effort between the military establishments of the Kingdom of Norway, the Russian Federation, and the United States. This paper discusses joint activities conducted over the past year among Norwegian, Russian, and U.S. technical experts on a project to develop, demonstrate and implement automated radiological monitoring at Russian Navy facilities engaged in the dismantlement of nuclear-powered strategic ballistic misșile launching submarines. Radiological monitoring is needed at these facilities to help protect workers engaged in the dismantlement program and the public living within the footprint of routine and accidental radiation exposure areas. By providing remote stand-alone monitoring, the Russian Navy will achieve added protection due to the defense-in-depth strategy afforded by local (at the site), regional (Kola) and national-level (Moscow) oversight. The system being implemented at the Polyarninsky Russian Naval Shipyard was developed from a working model tested at the Russian Institute for Nuclear Safety, Moscow, Russia. It includes Russian manufactured terrestrial and underwater gamma detectors, smart controllers for graded sampling, radio-modems for offsite transmission of the data, and a data fusion/display system: The data fusion/display system is derived from the Norwegian Picasso AMEC Environmental Monitoring software package. This computer package allows monitoring personnel to review the real-time and historical status of monitoring at specific sites and objects and to establish new monitoring protocols as required, for example, in an off-normal accident situation. Plans are being developed to implement the use of this system at most RF Naval sites handling spent nuclear fuel.
\end{abstract}

\section{INTRODUCTION}

This paper discusses joint activities conducted over the past year among Norwegian, Russian, and U.S. technical experts on a project to develop, demonstrate and implement remote radiological monitoring at Russian Navy facilities engaged in the dismantlement of nuclear-powered strategic ballistic missile launching submarines. Radiological monitoring is needed at these facilities to help protect workers engaged in the dismantlement program and the public living within the footprint of routine and accidental radiation exposure areas. By providing remote stand-alone monitoring, the Russian Navy will achieve added protection due to the defense-in-depth strategy afforded by local (at the site), regional (Kola) and national-level (Moscow) oversight.

AMEC Project Area 1.5 enhances Russia's ability to monitor radiation levels during submarine dismantlement through analysis of risk factors, equipment procurement, and improved personnel training. Several successful dosimetry-training programs have been conducted for Russian military officers at DOD and DOE facilities. Technologies and approaches for managing radiation hazards have also been shared. In addition, radiationmonitoring equipment has been transferred. Finally, a graphical interface software system was created and installed in 2000 to improve radioecological monitoring at sites handling and storing spent nuclear fuel from dismantled ballistic missile submarines. 


\section{PICASSO AMEC ENVIRONMENTAL MONITORING SYSTEM}

The PICASSO System was developed by the Institute for Energy Technology, OECD Halden Reactor Project, Halden, Norway. Picasso is tailor-made for developing dynamic graphical user interfaces. Data can be received from data acquisition systems, simulators, databases and/or other input sources, and the Graphical User Interface (GUI) is continuously updated to visualize the current state. PICASSO has been used for simulator systems and process surveillance and control systems in various application areas such as nuclear power plants, oil production platforms, telecommunication networks, electric power distribution, ship bridge systems, paper mills and environmental monitoring.

The PICASSO AMEC Environmental Monitoring System (Figure 1) includes:

- Multiple terrestrial and underwater smart gamma sensors to take regular radiation readings;

- "Smart" sensors that automatically increase the rate of sampling in the case of unusual readings

- Radio-modems for off-site transmission of data

- A computerized data fusion/display system to compile data and allow for real-time monitoring as well as historical comparisons.

Figure 2 presents a sample display screen of the PICASSO AMEC Environmental Monitoring System.

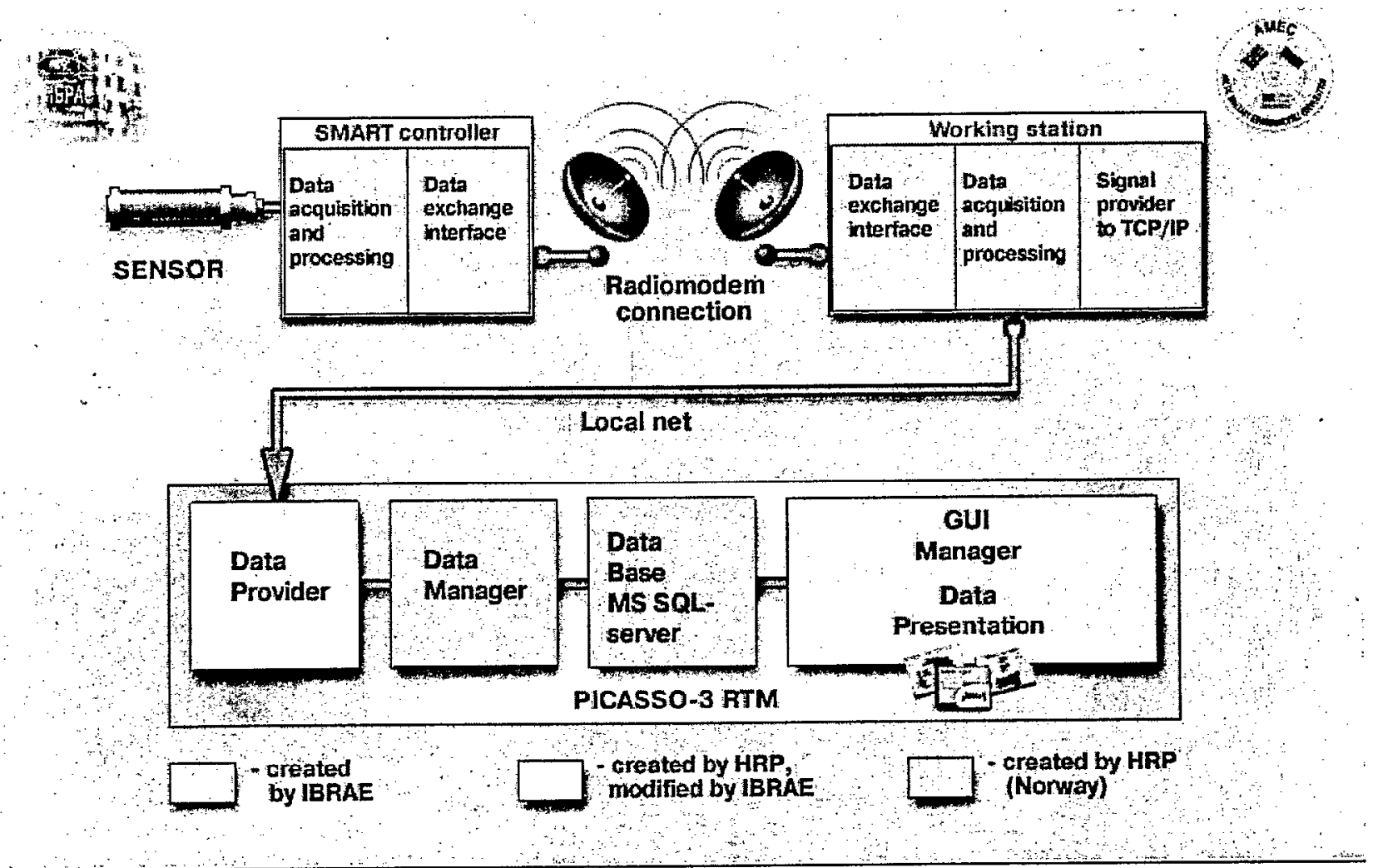

Figure 1. Block scheme of the system's working model. 


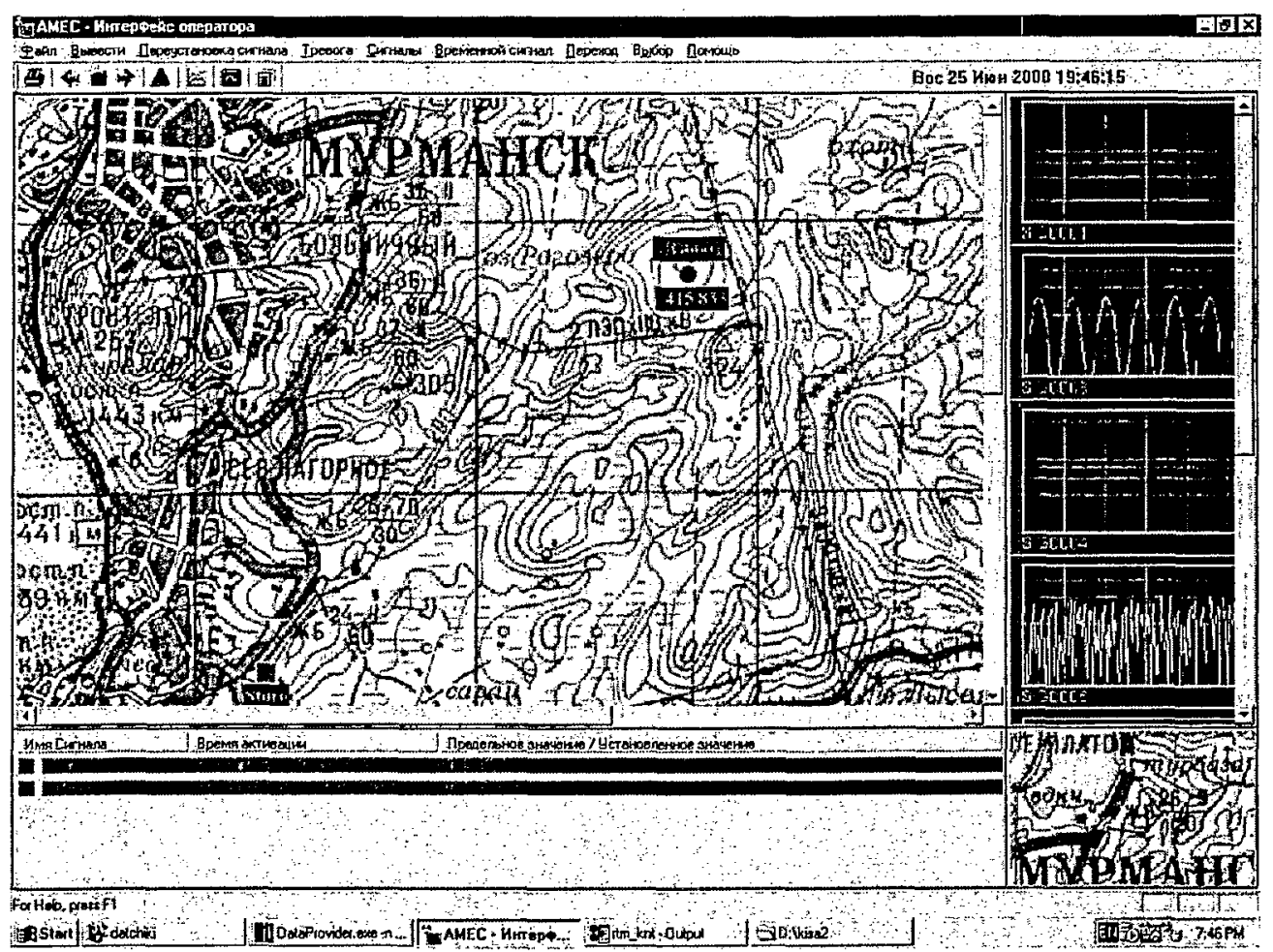

Figure 2. PICASSO AMEC Environmental Monitoring System Display Screen.

\section{POLYARNINSKY RUSSIAN FEDERATION NAVAL SHIPYARD}

The Russian Federation has almost 25 shipyards (in the Northwest proximate to the Barents Sea/Arctic Ocean and Far East proximate to the Sea of Japan and the Sea of Okhotsk/Pacific Ocean) servicing its naval nuclear operations. The Naval Shipyard at Polyarninsky was established in 1935. This facility serviced naval vessels during World War II. After World War II, the Navy expanded the facility. Beginning in August 1950 and was dedicated exclusively to military vessels, primarily submarines (Figure 3 ). Information presented below on this shipyard was derived from several open literature sources (1-4).

As the first nuclear powered submarines were delivered to the Northern Fleet at the end of the 1950s, the yard was modified for the docking and repair of these vessels. Tenders, service ships and dry docks were acquired, including the floating dock PD-63. At the present time, there are two covered floating docks at the yard constituting a total quay length of $700 \mathrm{~m}$. The yard has a surface area of $41330 \mathrm{~m}^{2}(446000 \mathrm{sq}$. ft.). There are approx. 3000 employees at the yard.

Repair and maintenance operations have been carried out on first, second and third generation nuclear submarines since 1962. Polyarninsky has participated in minimal dismantlement operations. Although refueling equipment is available at Polyarninsky, the future of refueling activities at Polyarninsky is also uncertain.

Polyarninsky operates a naval waste storage facility, and is the homeport for two service vessels engaged in submarine maintenance/defueling operations: the Pinega class Amur and the Vala class TNT-12. Solid radioactive waste is placed into containers and stored in an area specifically dedicated to this purpose. Two hundred containers and some large pieces of contaminated material have been placed outside the actual storage site that is full. There are plans to expand the storage facility or build an additional one, but so far there is no money allocated for this.

Liquid radioactive waste is stored in two floating tanks at the quay. The capacity of this storage is approximately $150 \mathrm{~m}^{3}$ (5300 cu. ft.). There are plans for establishing a storage facility for spent nuclear fuel in an existing tunnel near the shipyard, but no firm decision has been made. While the yard does possess equipment for the removal of fuel from both operational and inactive submarines, it is currently not in use. 


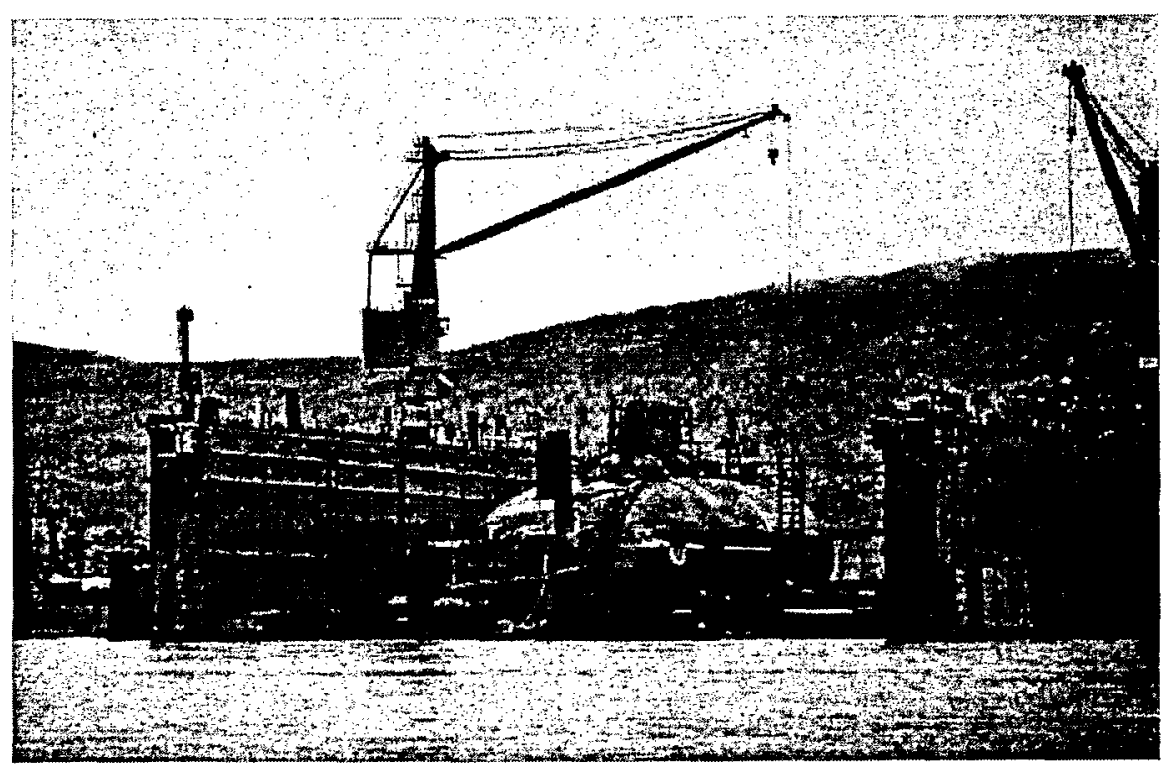

Figure 3: The naval yard Polyarninsky lies close to the city of Polyamyy. The shipyard has a storage facility for solid radioactive waste and two floating tanks containing liquid radioactive waste.

\section{PICASSO AMEC ENVIRONMENTAL MONTORING SYSTEM AT THE POLYARNINSKY NAVAL SHIPYARD}

The main goal of control for radiation pollution of the environment at naval sites, such as Polyarninsky, servicing and decommissioning nuclear powered submarines is to effectively manage radioactive materials during normal operation and accidental situations.

Decommissioning of nuclear powered submarines is a long-term and laborious process. It includes several major steps.

- Storage of floating nuclear submarines, brought out from active service.

- Off-loading of reactor cores under shipyards or base conditions.

- Off-loading, storage and transportation of irradiated nuclear fuel and radioactive waste.

- Dismantlement of the reactor compartment.

- Cleaning contaminated equipment.

- Long-term storage of three compartments blocks with reactors on water (with or without cores).

During each stage, radionuclides can be released to the environment and must therefore be managed. All of these enumerated stages of nuclear submarine decommissioning are very characteristic of the Polyarninsky Shipyard where the radiation monitoring system, PICASSO-AMEC will be implemented. Facilities to be monitored include the existing spent fuel, solid and liquid radioactive storage facilities as well as a new low-level waste storage site to be constructed as part of the AMEC Project 1.4 program (1) and a new mobile processing facility to be constructed as part of the AMEC Project 1.3 Program (2). These projects are described in detail in other reports presented at this conference.

At this site, the current radiological control system is limited and does not correspond to contemporary requirements for environmental safety. More specifically, the current radiation monitoring system is primarily based on field measurements taken with hand-held equipment. This equipment does not support comprehensive measurements of temporally and spatially variant radiation levels that are characteristically observed at this kind of a facility. Measurements of dynamic changes are particularly important because of the nature of the activities conducted at the site and the potential need for predictive forecasts in an accident situation. 
Analysis of impact of nuclear and radiation facilities to the environment shows that it is necessary to create complex and differential systems for permanent control taking into account the specific characteristics of operating conditions of the special units of shipyards. Automated systems, like PICASSO-AMEC, are very important as initial indicators of accidental situations and as providers of data for analytical, forecast and decision-making centers.

Radioecological monitoring must operate for ecological sites and must be based on landscape zoning for technical sites and surrounding areas (water areas) taking into account prevailing ways that the contamination may spread. This approach was not used before.

The most convenient form of data presentation is mapping system displaying information on radiation background, sites with higher content of artificial radionuclides, exposure rates, radioactive contamination and radiation threat level. The forecast functions are very important for both onsite and offsite locations.

In this context, the PICASSO-AMEC system being implemented at the Polyarninsky shipyard will help update and modernize radiation control practices at this site and will help provide better protection to the workers at the site and to civilian populations living near the site. Radiological monitoring is needed at this facility to help protect workers engaged in the dismantlement program and the public living within the footprint of routine and accidental radiation exposure areas.

\section{CONCLUSION}

Use of the PICASSO AMEC system will provide multiple layers of monitoring (both human and remote, locally and from offsite) that will increase the RF Navy's ability to detect elevated radiation levels and decrease the response time if a problem should arise. Further, by providing remote stand-alone monitoring, the Russian Navy will achieve added protection due to the defense-in-depth strategy afforded by local (at the site), regional (Kola) and national-lcvel (Moscow) oversight of its radiological monitoring program. Plans are being developed to implement the use of this system at most RF Naval sites handling spent nuclear fuel.

\section{REFERENCES}

1. Bellona Report nr.2:96. Written by: Thomas Nilsen, Igor Kudrik and Alexander Nikitin, http://spb.org.ru/bellona/ehome/russia/nfl/short/htm

2. Russia: Naval Nuclear Reactors: Nuclear Fleet:Northern Fleet, http://cns.miis.edu/cns/projects/nisnp/naval/nucflt/norflt/ff noflt.htm

3. Submarine Launched Ballistic Missile Facilities, http://sun00781.dn.net/nuke/guide/russia/facility/slbm/index.html

4. The Russian Northern Fleet, http://www.bellona.no/imaker?id=12675\&sub $=1$

5. B.T. Spargo, V. Engoy, V. Balkunov, P. Krumrine, S. Backe and S. Gorin, "Solid Radioactive Waste Treatment Initiatives for Nuclear Submarine Decommissioning Under the AMEC Program," Waste Management 01, Tuscon, Arizona, USA (2001).

6. Griffith, T. Engoy, A. Diashev, P. Schwab, and A. Nazarian, "Storage of Solid Radioactive Waste from the Northern Fleet of the Russian Navy under the AMEC Program," Waste Management 01, Tuscon, Arizona, USA (2001). 